\title{
Accelerated idioventricular rhythm
}

\author{
Avaneesh Jakkoju, MD, Rakesh Jakkoju, MD, Pramilla N. Subramaniam, MD, and D. Luke Glancy, MD
}

Section of Cardiology, Department of Medicine, Louisiana State University Health Sciences Center, New Orleans, Louisiana

KEYWORDS Idioventricular rhythm; ventricular tachycardia

A 60-year-old man with a history of high blood pressure, type 2 diabetes mellitus, end-stage kidney disease on hemodialysis, and a hemorrhagic stroke within the past year with neurologic residua was brought from the nursing home to the hospital because of fever and an altered mental state and was found to have pneumonia. Serum electrolytes were normal, and an echocardiogram showed normal left ventricular systolic function. A 12-lead electrocardiogram, however, was abnormal (Figure 1).
The initial portion of the electrocardiogram shows sinus rhythm at a rate of 65 beats per minute. The fifth QRS is premature and has a different morphology than the four previous QRSs. Thereafter, all of the QRSs are wide, and the rhythm is regular at a rate of 94 beats per minute. This is an accelerated idioventricular rhythm, and the fifth QRS is probably a fusion complex resulting from the simultaneous occurrence of the QRS of a supraventricular premature complex and the first idioventricular complex. The R-R

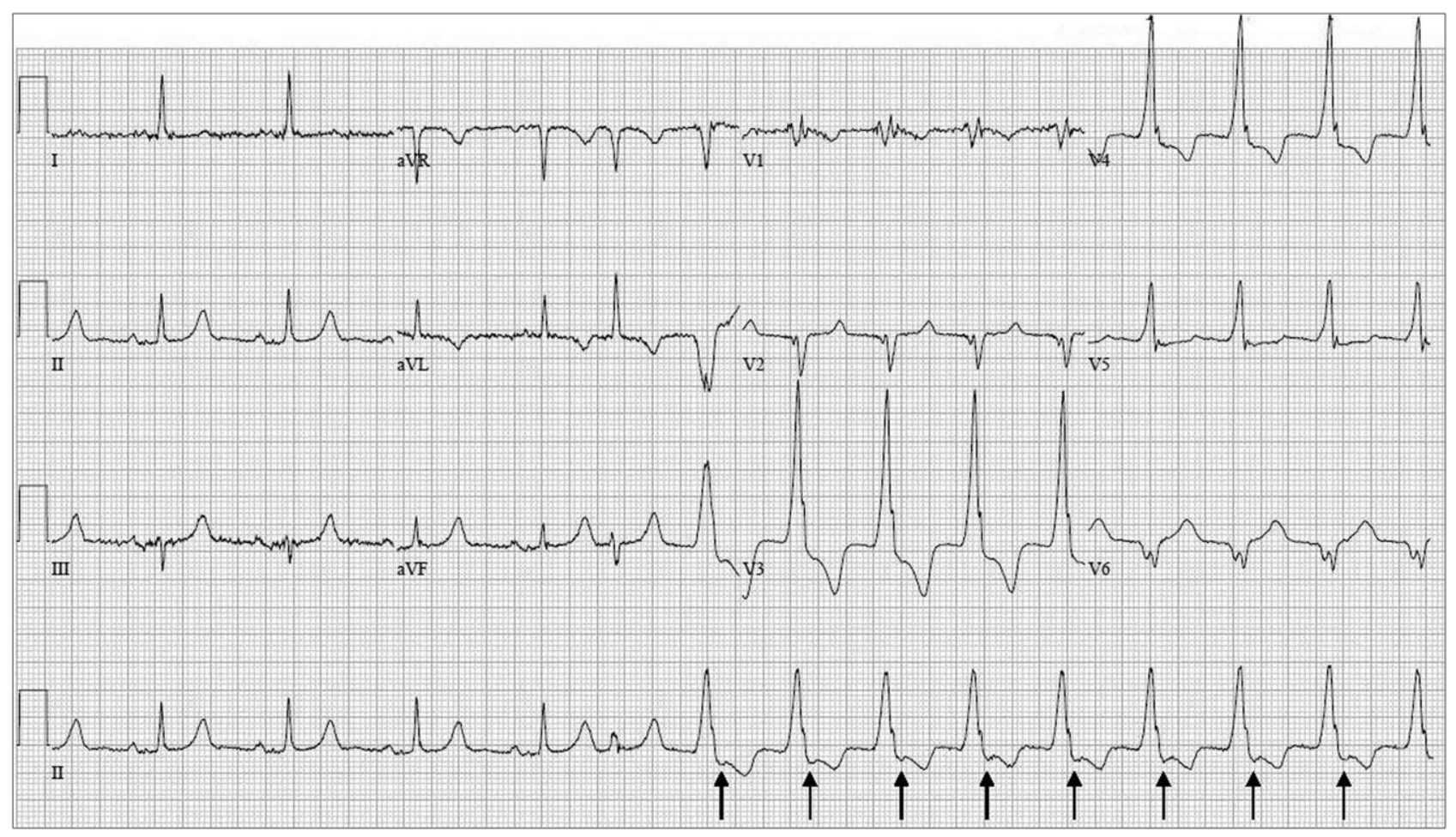

Figure 1. Electrocardiogram in a 60-year-old man admitted to the hospital from a nursing home because of fever and an altered mental state.

Corresponding author: D. Luke Glancy, MD, 1203 West Cherry Hill Loop, Folsom, LA 70437 (e-mail: dglanc@|suhsc.edu) Received April 20, 2018; Accepted April 26, 2018. 
interval between the fifth and sixth QRSs is identical to all of the subsequent R-R intervals.

During sinus rhythm, the $\mathrm{P}$ waves in lead II are upright, broad $(0.15 \mathrm{~s})$, and notched, suggesting left atrial enlargement. During the idioventricular rhythm, the $\mathrm{P}$ waves in lead II occur at the end of the QRSs (arrows) and are inverted, as would be expected with retrograde $P$ waves.

Accelerated idioventricular rhythm is essentially a slow (rate 60 to 110 beats per minute) ventricular tachycardia that usually occurs in patients with heart disease. It is often seen in patients with acute myocardial infarction, and in that setting there may also be an increased occur- rence of ventricular tachycardia. ${ }^{1,2}$ Accelerated idioventricular rhythm is usually transient, is often asymptomatic, and rarely requires treatment. ${ }^{3}$

1. de Soyza ND, Bissett JK, Kane JJ, Murphy ML, Doherty JE. Association of accelerated idioventricular rhythm and paroxysmal ventricular tachycardia in acute myocardial infarction. Am $\mathrm{J}$ Cardiol. 1974;34:667-670. doi:10.1016/0002-9149(74)90155-6.

2. Lichstein E, Ribas-Merecliar C, Gupta PK, Chadda KD. Incidence and description of accelerated ventricular rhythm complicating acute myocardial infarction. Am J Med. 1975;58:192-198.

3. Prystowsky EN, Klein GJ. Cardiac Arrhythmias. An Integrated Approach for the Clinician. New York, NY: McGraw-Hill; 1994.

\section{Avocations}

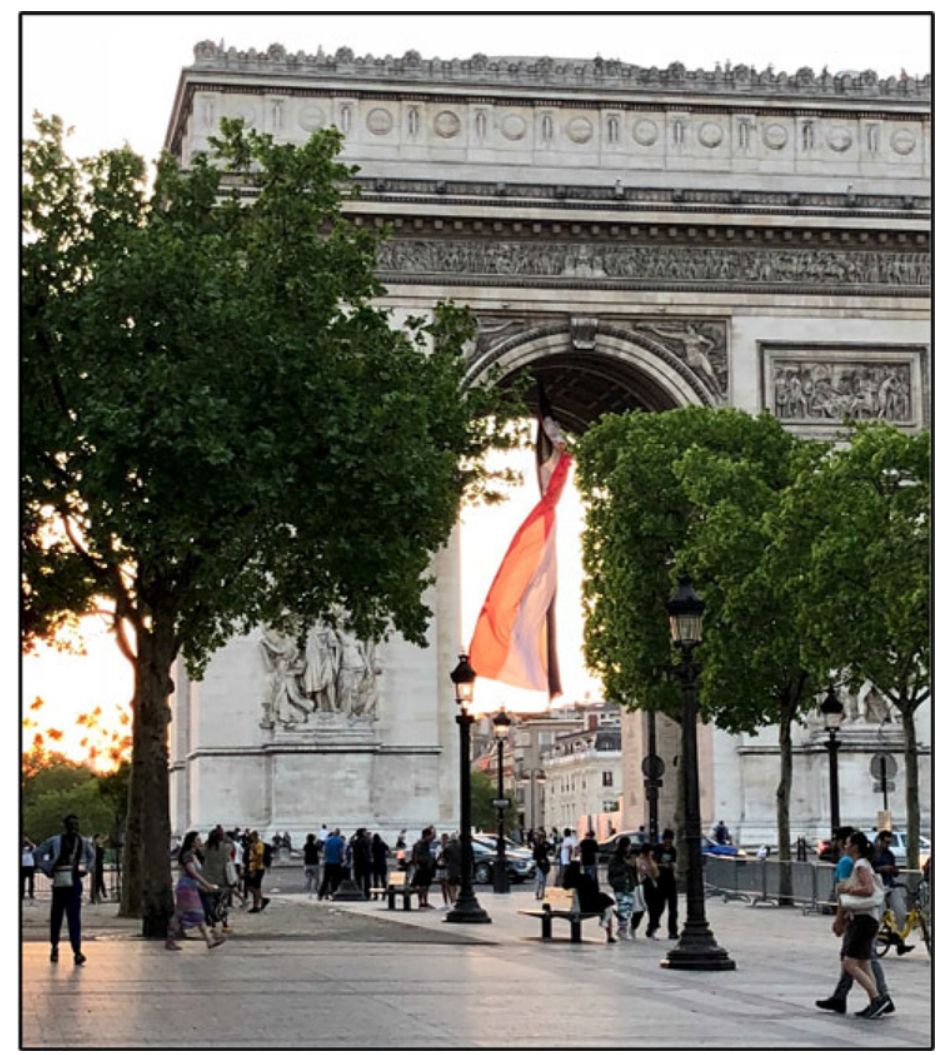

VE Day in Paris, France, 2018. Copyright (C) Jeffrey Michel, MD, interim chief, Cardiology Division, Baylor Scott \& White, Temple, Texas (e-mail: jeffrey.michel@bswhealth.org). 